\title{
Comparative Study of Conventional, Fuzzy Logic and Neural PID Speed Controllers with Torque Ripple Minimization for an Axial Magnetic Flux Switched Reluctance Motor
}

\author{
Eric S. Sanches, José A. Santisteban \\ Electrical Engineering Department, Mechanical Engineering Postgraduate Program (PGMEC), Fluminense \\ Federal University, Niterói, Brazil \\ Email: ericsanches@vm.uff.br, jasantisteban@vm.uff.br
}

Received 31 July 2014; revised 25 August 2014; accepted 8 September 2014

Copyright (C) 2014 by authors and Scientific Research Publishing Inc.

This work is licensed under the Creative Commons Attribution International License (CC BY). http://creativecommons.org/licenses/by/4.0/

(c) (;)

\begin{abstract}
Three speed controllers for an axial magnetic flux switched reluctance motor with only one stator, are described and experimentally tested. As it is known, when current pulses are imposed in their windings, high ripple torque is obtained. In order to reduce this ripple, a control strategy with modified current shapes is proposed. A workbench consisting of a machine prototype and the control system based on a microcontroller was built. These controllers were: a conventional PID, a fuzzy logic PID and a neural PID type. From experimental results, the effective reduction of the torque ripple was confirmed and the performance of the controllers was compared.
\end{abstract}

\section{Keywords}

Axial Flux SRM, PID Speed Controller, Fuzzy Logic PID Speed Controller, Neural PID Speed Controller, Torque Ripple Minimization, Current Shape Control Strategy

\section{Introduction}

The radial magnetic flux version of switched reluctance motors (SRM) has been widely used in many variable speed industrial applications and some advantages have been reported: high torque output, wide range of operating speed, geometrical simplicity, reliability and robustness [1] [2]. In the case of an axial flux SRM (AFSRM) the air gap magnetic flux is parallel to the rotation axis. As the AFSRM can have a smaller axis length than the radial magnetic flux motor, it is believed that it is a good solution for use in applications where size is important, 
as in electric cars, for instance.

The switched reluctance motor (SRM) analyses are complex because of their doubly salient pole structure and nonlinear magnetic characteristics. The developed torque is a nonlinear function of the currents applied to the stator windings and their inductances, which depend on the rotor position. Nevertheless, with an appropriate control system, minimum ripple torque can be obtained.

From literature, it can be observed that many works are related to radial flux SRM; however few works are related to axial flux SRM [3]. Some of them refer to axial flux SRM with two stators [4]-[6], but in this paper the motor has only one stator. With respect to the control strategies, several strategies are reported [7]-[9].

For ordinary radial flux SRM, the mutual inductances of the stator windings are considered small [10] and most researchers do not take them into account. For AFSRM this is not true because the magnetic flux paths are quite different to those found in radial flux SRM. In this work, the AFSRM self and mutual inductances were estimated based on the three-dimensional finite element method and then they were used in the motor electromechanical model.

When voltages or current pulses are imposed in the stator windings, the level of torque ripple is high, if compared with other kind of motors, which is the primary disadvantage of SRM as it contributes to the vibration and acoustic noise. For this reason, the imposition of different current shapes to reduce the torque ripple appears as an interesting solution. In this work, the procedure to obtain alternatives shapes is described and the effectiveness of this strategy is experimentally tested in an AFSRM prototype. Even more, in order to evaluate the performance of different kinds of speed controllers, three PID types were implemented: a conventional, a fuzzy logic and a neural based approach. Although in different levels the experimental results confirm the reduction of torque ripple, there are also differences with respect to the execution time and the speed response.

\section{The Axial Flux SRM Prototype}

The prototype has six poles in the stator, corresponding to three phases (" $a$ ", " $b$ " and " $c$ "), and four poles in the rotor. It is a 3-phase 6/4 poles AFSRM, shown in Figure 1.

The characteristics of the 3-phase 6/4 AFSRM prototype are shown in Table 1.

\begin{tabular}{cc} 
Table 1. The characteristics of the 3-phase 6/4 axial flux SRM. \\
\hline Parameter & Value \\
\hline Outer diameter of rotor and stator & $126 \mathrm{~mm}$ \\
Inner diameter of rotor and stator poles & $63 \mathrm{~mm}$ \\
Shaft diameter & $40 \mathrm{~mm}$ \\
Air gap & $1.9 \mathrm{~mm}$ \\
Stator pole width & $34 \mathrm{~mm}$ \\
Rotor pole width & $26 \mathrm{~mm}$ \\
Stator and rotor poles arc & $40^{\circ}$ \\
Poles radial length & $31.5 \mathrm{~mm}$ \\
Stator yoke thickness & $5 \mathrm{~mm}$ \\
Stator pole area (axial cross-section) & $1039 \mathrm{~mm}{ }^{2}$ \\
Rotor yoke thickness & $17 \mathrm{~mm}$ \\
Number of turns per stator pole & 175 \\
Turn wire & $24 \mathrm{AWG}$ \\
Coil resistance & $2.3 \Omega$ \\
Motor shaft material & Steel SAE-1020 \\
\hline
\end{tabular}




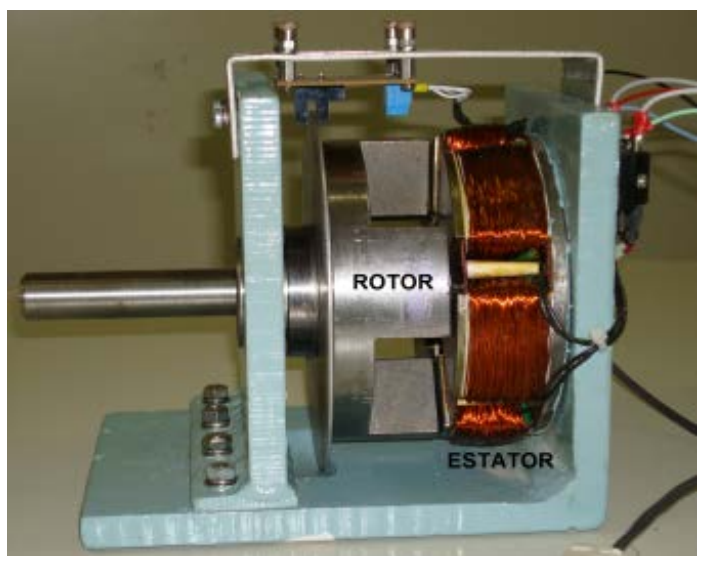

Figure 1. The AFSRM prototype.

Each stator pole has one coil, so there are six coils named " $a 1$ ", “ $a 2$ ", " $b 1$ ”, " $b 2$ ", “ $c 1$ ” and "c2".

The stator and rotor cores were solid because the objective of this work was the torque ripple minimization and not the loss reduction.

\section{Torque Ripple Minimization Strategy}

Considering that the motor core is operating in the linear region, the net electromagnetic torque $T_{e}$ for the three phase AFSRM prototype is found as:

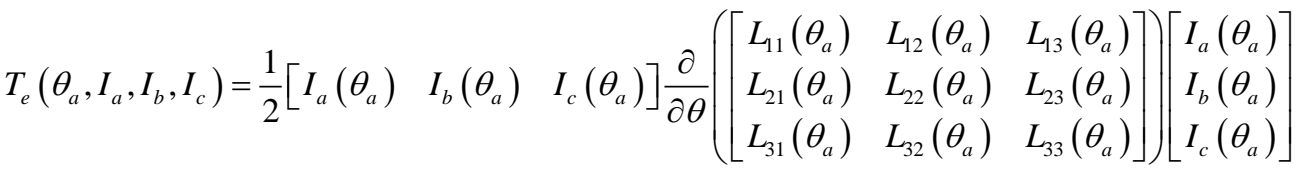

$$
\begin{aligned}
& L_{11}\left(\theta_{a}\right)=+L_{a 1 a 1}\left(\theta_{a}\right)+M_{a 2 a 1}\left(\theta_{a}\right)+M_{a 1 a 2}\left(\theta_{a}\right)+L_{a 2 a 2}\left(\theta_{a}\right) \\
& L_{12}\left(\theta_{a}\right)=+M_{b 1 a 1}\left(\theta_{a}\right)-M_{b 2 a 1}\left(\theta_{a}\right)-M_{b 1 a 2}\left(\theta_{a}\right)+M_{b 2 a 2}\left(\theta_{a}\right) \\
& L_{13}\left(\theta_{a}\right)=-M_{c 1 a 1}\left(\theta_{a}\right)+M_{c 2 a 1}\left(\theta_{a}\right)+M_{c 1 a 2}\left(\theta_{a}\right)-M_{c 2 a 2}\left(\theta_{a}\right) \\
& L_{21}\left(\theta_{a}\right)=+M_{a 1 b 1}\left(\theta_{a}\right)-M_{a 2 b 1}\left(\theta_{a}\right)-M_{a 1 b 2}\left(\theta_{a}\right)+M_{a 2 b 2}\left(\theta_{a}\right) \\
& L_{22}\left(\theta_{a}\right)=+L_{b 1 b 1}\left(\theta_{b}\right)+M_{b 2 b 1}\left(\theta_{b}\right)+M_{b 1 b 2}\left(\theta_{b}\right)+L_{b 2 b 2}\left(\theta_{b}\right) \\
& L_{23}\left(\theta_{a}\right)=+M_{c 1 b 1}\left(\theta_{b}\right)-M_{c 2 b 1}\left(\theta_{b}\right)-M_{c 1 b 2}\left(\theta_{b}\right)+M_{c 2 b 2}\left(\theta_{b}\right) \\
& L_{31}\left(\theta_{a}\right)=-M_{a 1 c 1}\left(\theta_{a}\right)+M_{a 2 c 1}\left(\theta_{a}\right)+M_{a 1 c 2}\left(\theta_{a}\right)-M_{a 2 c 2}\left(\theta_{a}\right) \\
& L_{32}\left(\theta_{a}\right)=+M_{b 1 c 1}\left(\theta_{b}\right)-M_{b 2 c 1}\left(\theta_{b}\right)-M_{b 1 c 2}\left(\theta_{b}\right)+M_{b 2 c 2}\left(\theta_{b}\right) \\
& L_{33}\left(\theta_{a}\right)=+L_{c 1 c 1}\left(\theta_{c}\right)+M_{c 2 c 1}\left(\theta_{c}\right)+M_{c 1 c 2}\left(\theta_{c}\right)+L_{c 2 c 2}\left(\theta_{c}\right)
\end{aligned}
$$

where: $L$ and $M$ stand for the self and mutual inductances.

The rotor position angle $\theta_{a}$, for phase " $a$ ", is considered as $45^{\circ}$ when the rotor pole was completely overlapping with the stator pole, as depicted in Figure 2, and this angle is measured clockwise.

The $\theta_{b}$ and $\theta_{c}$ angles correspond to rotor angular positions for phases " $b$ " and "c", respectively. The relationships between these angles are:

- for $\theta_{a} \leq 30^{\circ}$

$$
\begin{aligned}
& \theta_{b}=\theta_{a}+30^{\circ} \\
& \theta_{c}=\theta_{a}+60^{\circ}
\end{aligned}
$$




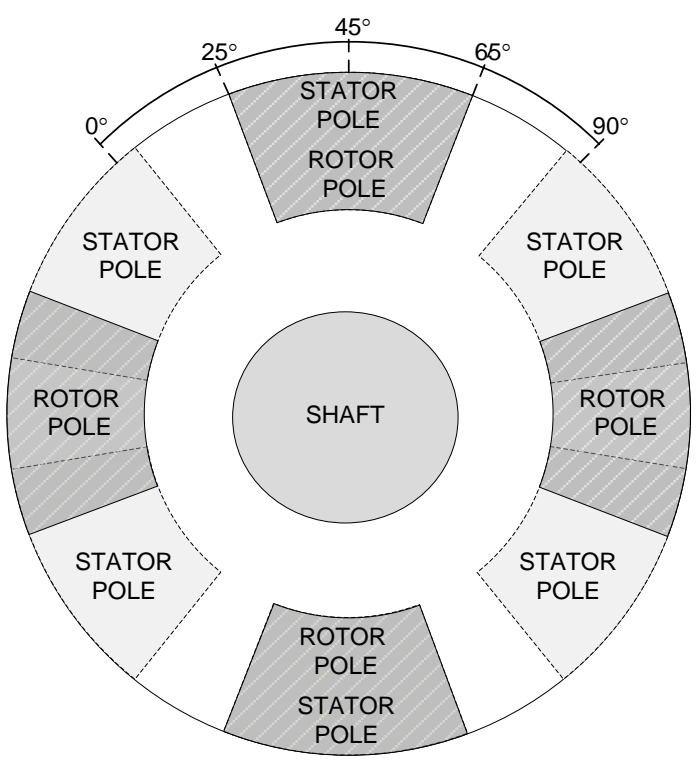

Figure 2. Position of rotor pole $45^{\circ}$ relative to stator pole of the AFSRM prototype.

- for $30^{\circ}<\theta_{a} \leq 60^{\circ}$

$$
\begin{aligned}
& \theta_{b}=\theta_{a}+30^{\circ} \\
& \theta_{c}=\theta_{a}-30^{\circ}
\end{aligned}
$$

- for $60^{\circ}<\theta_{a} \leq 90^{\circ}$

$$
\begin{aligned}
& \theta_{b}=\theta_{a}-60^{\circ} \\
& \theta_{c}=\theta_{a}-30^{\circ}
\end{aligned}
$$

The relationship among the three phases self and mutual inductances are: $L_{a 2 a 2}\left(\theta_{a}\right)=L_{a 1 a 1}\left(\theta_{a}\right) ; L_{b 1 b 1}\left(\theta_{b}\right)=$ $L_{a 1 a 1}\left(\theta_{b}\right) ; L_{b 2 b 2}\left(\theta_{b}\right)=L_{b 1 b 1}\left(\theta_{b}\right) ; L_{c 1 c 1}\left(\theta_{c}\right)=L_{a 1 a 1}\left(\theta_{c}\right) ; L_{c 2 c 2}\left(\theta_{c}\right)=L_{c 1 c 1}\left(\theta_{c}\right) ; M_{a 2 a 2}\left(\theta_{a}\right)=M_{a 1 a 2}\left(\theta_{a}\right) ; M_{a 2 b 1}\left(\theta_{a}\right)=$ $M_{a 1 b 2}\left(\theta_{a}\right) ; M_{a 2 b 2}\left(\theta_{a}\right)=M_{a 1 b 1}\left(\theta_{a}\right) ; M_{a 2 c 1}\left(\theta_{a}\right)=M_{a 1 c 2}\left(\theta_{a}\right) ; M_{a 2 c 2}\left(\theta_{a}\right)=M_{a 1 c 1}\left(\theta_{a}\right), M_{b 1 a 1}\left(\theta_{a}\right)=M_{a 1 b 1}\left(\theta_{a}\right) ; M_{b 1 a 2}\left(\theta_{a}\right)=$ $M_{a 2 b 1}\left(\theta_{a}\right) ; M_{b 1 b 2}\left(\theta_{b}\right)=M_{a 1 a 2}\left(\theta_{b}\right) ; M_{b 1 c 1}\left(\theta_{b}\right)=M_{a 1 b 1}\left(\theta_{b}\right) ; M_{b 1 c 2}\left(\theta_{b}\right)=M_{a 1 b 2}\left(\theta_{b}\right) ; M_{b 2 a 1}\left(\theta_{a}\right)=M_{a 1 b 2}\left(\theta_{a}\right) ; M_{b 2 a 2}\left(\theta_{a}\right)=$ $M_{a 2 b 2}\left(\theta_{a}\right) ; M_{b 2 b 1}\left(\theta_{b}\right)=M_{b 1 b 2}\left(\theta_{b}\right) ; M_{b 2 c 1}\left(\theta_{b}\right)=M_{b 1 c 2}\left(\theta_{b}\right) ; M_{b 2 c 2}\left(\theta_{b}\right)=M_{b 1 c 1}\left(\theta_{b}\right) ; M_{c 1 a 1}\left(\theta_{a}\right)=M_{a 1 c 1}\left(\theta_{a}\right) ; M_{c 1 a 2}\left(\theta_{a}\right)=$ $M_{a 2 c 1}\left(\theta_{a}\right) ; M_{b 2 b 1}\left(\theta_{b}\right)=M_{b 1 b 2}\left(\theta_{b}\right) ; M_{c 1 b 1}\left(\theta_{b}\right)=M_{b 1 c 1}\left(\theta_{b}\right) ; M_{c 1 b 2}\left(\theta_{b}\right)=M_{b 2 c 1}\left(\theta_{b}\right) ; M_{c 1 c 2}\left(\theta_{c}\right)=M_{a 1 a 2}\left(\theta_{c}\right) ; M_{c 2 a 1}\left(\theta_{a}\right)=$ $M_{a 1 c 2}\left(\theta_{a}\right) ; M_{c 2 a 2}\left(\theta_{a}\right)=M_{a 2 c 2}\left(\theta_{a}\right) ; M_{c 2 b 1}\left(\theta_{b}\right)=M_{b 1 c 2}\left(\theta_{b}\right) ; M_{c 2 b 2}\left(\theta_{b}\right)=M_{b 2 c 2}\left(\theta_{b}\right) ;$ and $M_{c 2 c 1}\left(\theta_{c}\right)=M_{c 1 c 2}\left(\theta_{c}\right)$.

The self and mutual inductances were estimated based on a simulation model using a three dimensional finite element method of the "ANSYS Multiphysics" software [11] with magneto static analysis. The 96 type solid elements were used in the simulation software.

In Figure 3, for eleven rotor positions, the self and mutual inductances estimated, for phase " $a$ ", are shown. The self-inductance is represented by $L_{a 1 a 1}$ and the mutual inductances are named $M_{a 1 a 2}, M_{a 1 b 1}, M_{a 1 b 2}, M_{a 1 c 1}$ and $M_{a 1 c 2}$, respectively.

As shown in Figure 3, the self-inductance has a similar profile to the radial flux SRM case, which means that the minimum inductance corresponds to the unaligned position (no overlap between rotor and stator poles) while the maximum inductance corresponds to the full alignment position between rotor and stator poles. The inductances profiles repeat every $90^{\circ}$.

From Figure 3, it can be noted that the mutual inductances between the coil " $a 1$ " and the other five coils are not negligible. For instance, the maximum relationship between them $\left(M_{a 1 b 1} / L_{a 1 a 1}\right)$ is around 0.25 near $20^{\circ}$.

In this way, in order to provide a constant electromagnetic torque for all rotor positions, appropriated reference currents should be designed. From previous tests in open loop [12], the best current feed strategy consists of the following sequence of energizing the windings: 


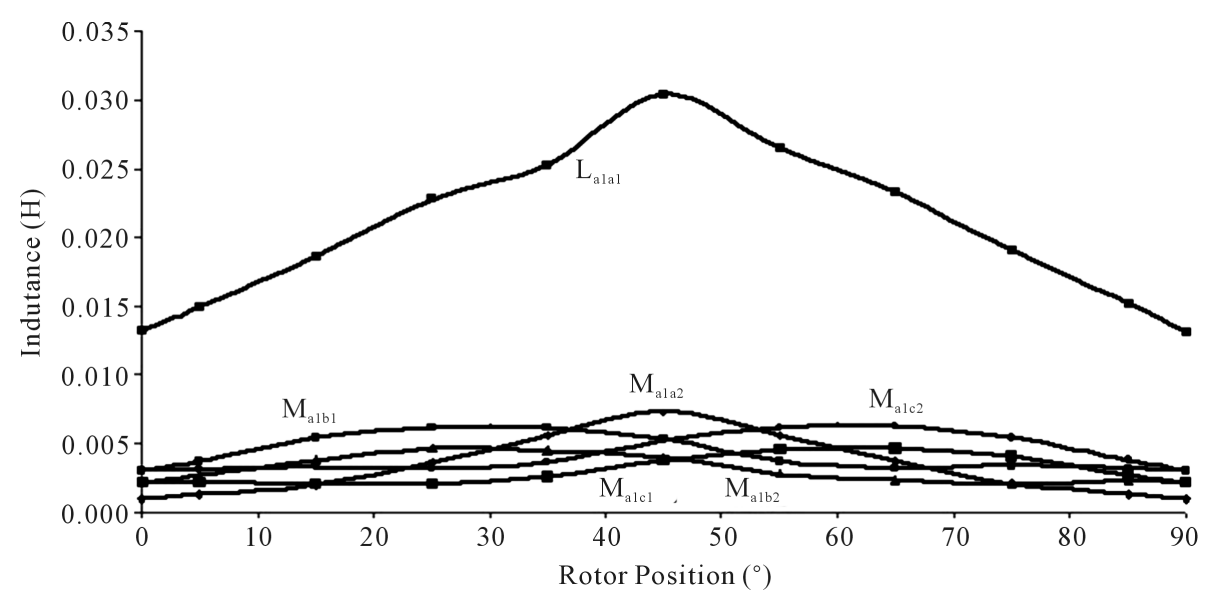

Figure 3. AFSRM self and mutual inductances.

- phases " $a$ " and " $b$ " from rotor position $0^{\circ}$ to $15^{\circ}$;

- only phase " $a$ " from rotor position $15^{\circ}$ to $30^{\circ}$;

- phases " $a$ " and " $c$ " from rotor position $30^{\circ}$ to $45^{\circ}$;

- only phase " $c$ " from rotor position $45^{\circ}$ to $60^{\circ}$;

- phases " $b$ " and " $c$ " from rotor position $60^{\circ}$ to $75^{\circ}$;

- only phase " $b$ " from rotor position $75^{\circ}$ to $90^{\circ}$.

This cycle repeats each $90^{\circ}$.

On the other hand, to define a reference torque without harmonics, it was considered as that generated when a current of $3 \mathrm{~A}$ is imposed in phase " $a$ ", while the rotor position was $30^{\circ}$. In this situation a net electromagnetic torque of $0.126 \mathrm{Nm}$ was calculated.

Next, for every one degree, the current values of the phase " $a$ " were calculated as:

- from rotor position $15^{\circ}$ to $30^{\circ}$

$$
I_{a}\left(\theta_{a}\right)=\sqrt{\frac{0.126}{\frac{\partial L_{a 1 a 1}\left(\theta_{a}\right)}{\partial \theta_{a}}+\frac{\partial L_{a 1 a 2}\left(\theta_{a}\right)}{\partial \theta_{a}}}}
$$

- from rotor position $0^{\circ}$ to $15^{\circ}$ a function that starts in zero and it then assumes the value calculated with (17) in the rotor position of $15^{\circ}$, was used

$$
I_{a}\left(\theta_{a}\right)=2.7967-2.7967 \mathrm{e}^{\left(-\theta_{a} / 4\right)}
$$

- from rotor position $30^{\circ}$ to $45^{\circ}$ the $I_{a}$ current values are calculated from quadratic Equation (19) considering that $I_{c}$ assumes the values of $I_{a}$ currents obtained from (18). For example, the $I_{c}$ value for $35^{\circ}$ is equal to the $I_{a}$ value for $5^{\circ}$

$$
\begin{aligned}
& \left(\frac{\partial L_{a 1 a 1}\left(\theta_{a}\right)}{\partial \theta_{a}}+\frac{\partial L_{a 1 a 2}\left(\theta_{a}\right)}{\partial \theta_{a}}\right) I_{a}^{2}\left(\theta_{a}\right)+\left[\left(\frac{-2 \partial L_{a 1 c 1}\left(\theta_{a}\right)}{\partial \theta_{a}}+\frac{2 \partial L_{a 1 c 2}\left(\theta_{a}\right)}{\partial \theta_{a}}\right) I_{c}\left(\theta_{a}\right)\right] I_{a}\left(\theta_{a}\right) \\
& +\left(\frac{\partial L_{c 1 c 1}\left(\theta_{a}\right)}{\partial \theta_{a}}+\frac{\partial L_{c 1 c 2}\left(\theta_{a}\right)}{\partial \theta_{a}}\right) I_{c}^{2}\left(\theta_{a}\right)-0.126=0
\end{aligned}
$$

The reference currents of phases " $c$ " and " $b$ " are shifted by $30^{\circ}$ and $60^{\circ}$ relative to phase current " $a$ ". All these reference currents are shown in Figure 4.

\section{Controllers Description}

In order to evaluate the performance of different kinds of speed controllers, three PID types were implemented: a conventional, a fuzzy logic and a neural based approach. 
In Figure 5, the conventional PID structure is shown. As noted, the current references are obtained multiplying the controller output by a table with three outputs, which depend on the angular position of the rotor. In our experiments, two tables were evaluated. In the first one, the outputs have pulsed shapes. The final effect is a torque with high ripple components. In the second case, the outputs have modified shapes according to Figure 4. As the experimental results show, the reduction of torque ripple is important.

In this case, the PID gains were adjusted by simulations using MatLab ${ }^{\circledR}$ Simulink software, resulting in gains proportional, integral and derivative, of 16, 3 and 1, respectively.

The controller output was limited to the interval of $[0,1]$.

In Figure 6, the fuzzy or neural control structure is shown. As noted, the outputs of the controller are directly the current references for the AFSRM.

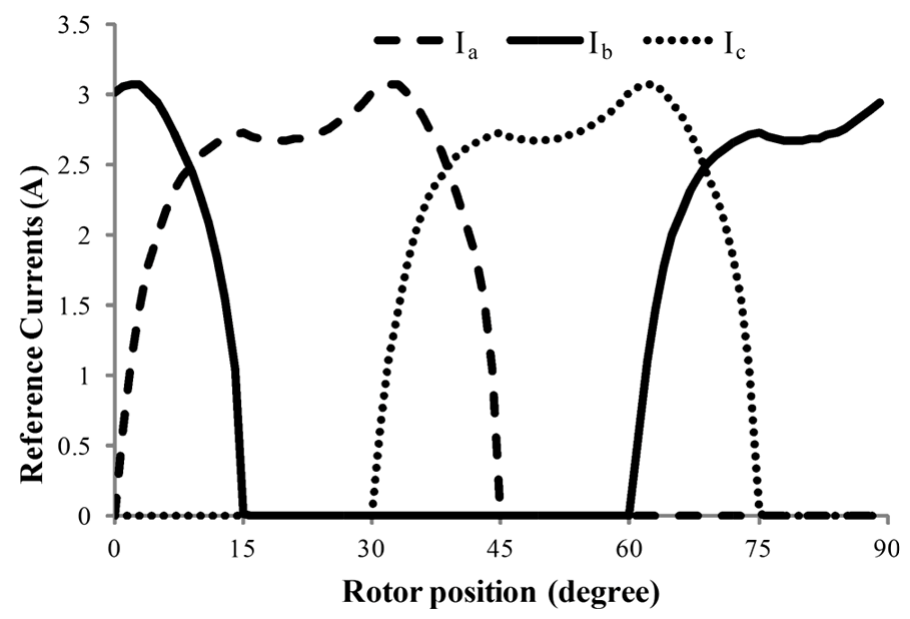

Figure 4. Reference currents waveforms.

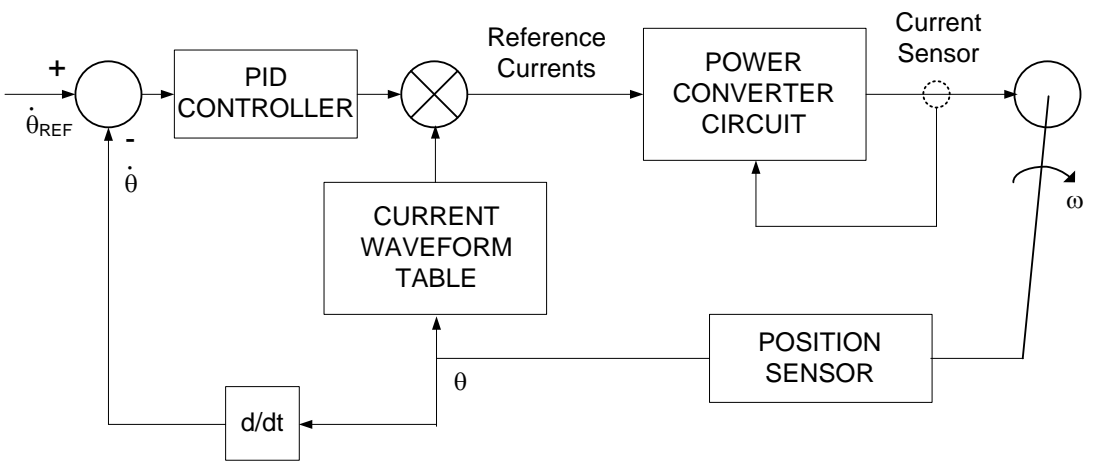

Figure 5. Block diagram of the PID speed control system.

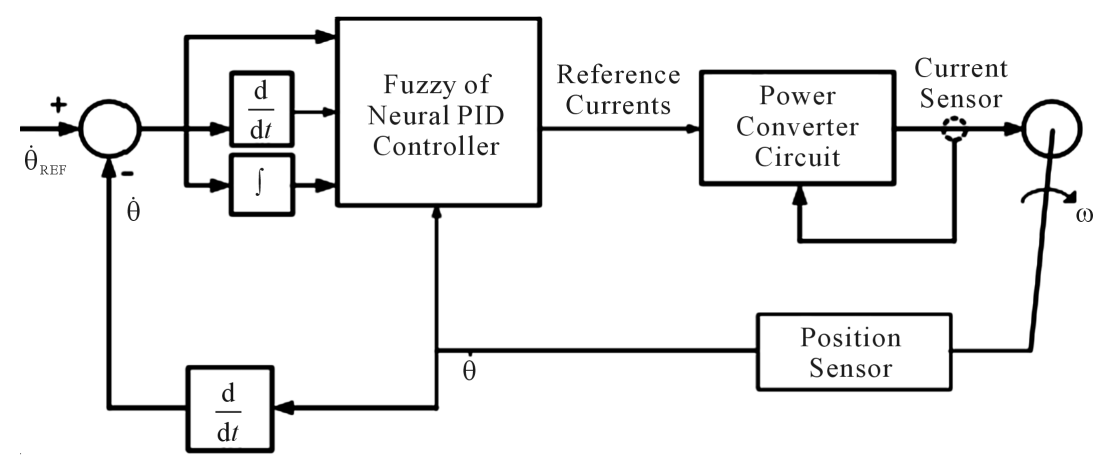

Figure 6. Block diagram of the fuzzy or neural PID speed control system. 
In the case of the fuzzy controller, the rules were based on the observation of the simulation results of the PID controller that use the modified current shapes. The inputs of the fuzzy logic controller were speed error, derivative of speed error, integral of speed error and angular rotor position. The output variables are the three phase's reference currents. In the actual implementation, this strategy was translated to a table.

The fuzzy logic characteristics used in MatLab ${ }^{\circledR}$ Simulink simulations are: minimum "And" Method, maximum “Or” Method, minimum "Implication”, maximum “Aggregation” and centroid "Defuzzification”.

The input variable speed error ("E”) has three linguistic values: "negative”, "zero" and "positive”. The corresponding membership functions are:

- trapezoidal type $\left[\begin{array}{cccc}-50 & -50 & -1 & 0\end{array}\right]$ for “negative” (“N”);

- triangular type $\left[\begin{array}{lll}-1 & 0 & 1\end{array}\right]$ “zero" (“Z”);

- trapezoidal type [ $\left[\begin{array}{llll}0 & 1 & 350 & 350\end{array}\right]$ for "positive” (“P”).

The input variable derivative of speed error ("CE”) has three linguistic values: "negative”, "zero" and "positive”. The corresponding membership functions are:

- triangular type $\left[\begin{array}{lll}-20 & -20 & 0\end{array}\right]$ for "negative” (“N”);

- triangular type $\left[\begin{array}{lll}-20 & 0 & 20\end{array}\right]$ for "zero" (“Z”);

- trapezoidal type $\left[\begin{array}{lll}0 & 20 & 20\end{array}\right]$ for "positive” (“P”).

The input variable integral of speed error ("IE”) has three linguistic values: "negative”, "zero" and "positive”.

The corresponding membership functions are:

- triangular type $\left[\begin{array}{lll}-10 & -10 & 0\end{array}\right]$ for "negative" (“N”);

- triangular type $\left[\begin{array}{lll}-10 & 0 & 10\end{array}\right]$ for "zero" (“Z”);

- triangular type $\left[\begin{array}{lll}0 & 10 & 10\end{array}\right]$ for “positive” (“P”).

The input variable angular rotor position ("Pos”) has ten linguistic values: “P1”, “P2”, “P3”, "P4”, "P5”, “P6”, "P7", "P8", "P9" and "P10”, whose corresponding membership functions are shown in Figure 7.

The output variables are the three phase’s reference currents. They have four linguistic values: "zero" ("Z”), "low” ("L”), "medium” ("M") and "high” ("H”). The corresponding membership functions for phase " $a$ " current are shown in Figure 8.

Take into account the number of membership functions, there are $270(3 \times 3 \times 3 \times 10)$ fuzzy rules. Its structure is similar to: if (E is "P") and (CE is " $\mathrm{P}$ ") and (IE is "N") and (Pos is "P5") then ( $I_{a}$ is "M") ( $I_{b}$ is " $\mathrm{Z}$ ") $\left(I_{c}\right.$ is "H”).

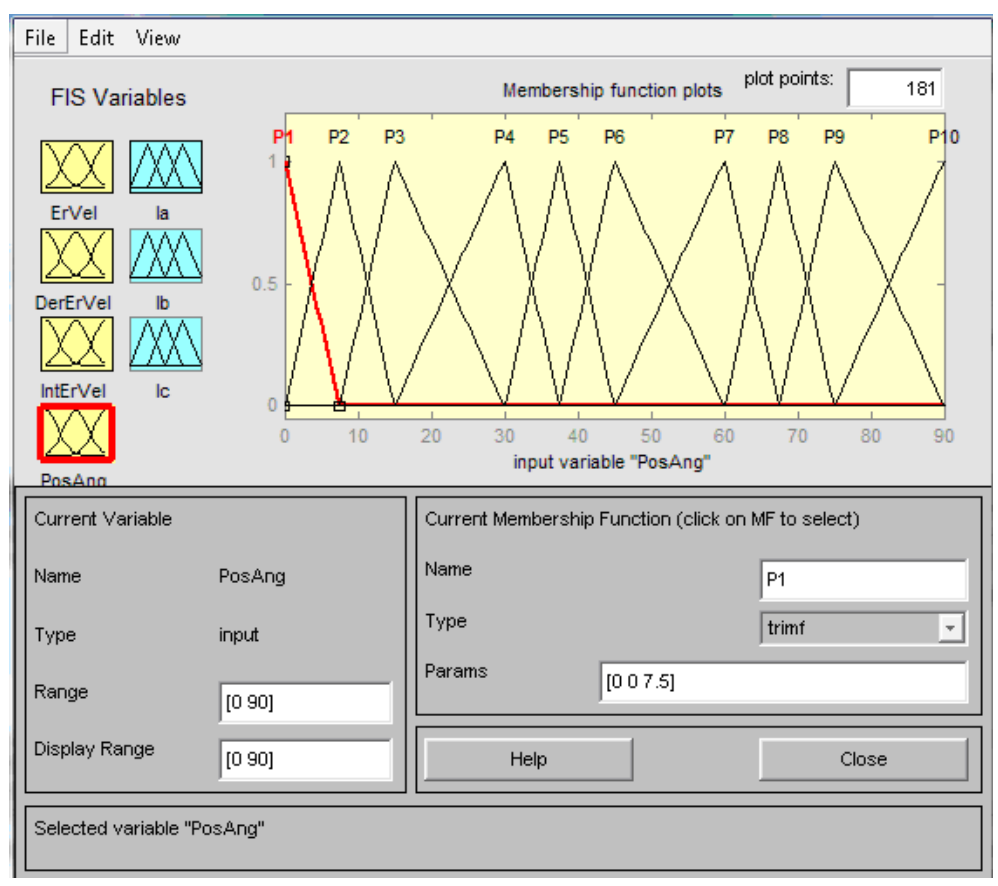

Figure 7. Membership functions of input variables of the fuzzy speed controller. 


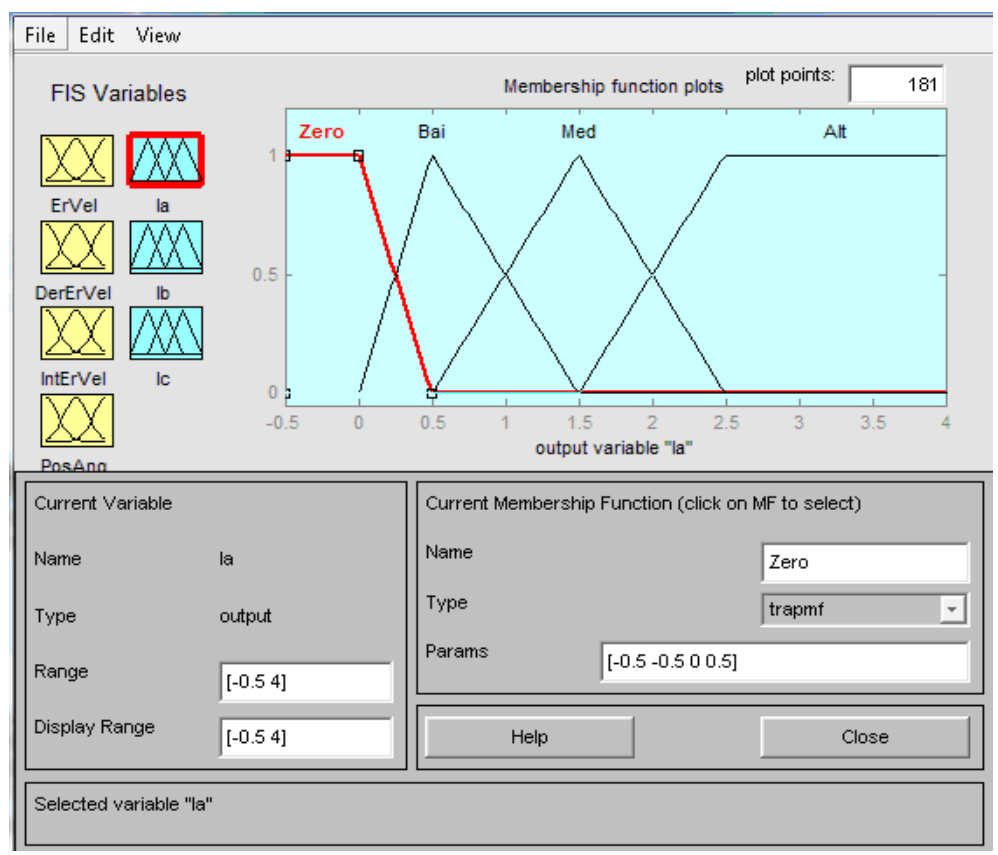

Figure 8. Membership functions of output variables of the fuzzy speed controller.

For the neural PID controller design, the usual procedure of off-line training was adopted. This was based in the data, with sampling frequency of $1 \mathrm{kHz}$, from the simulation results of the PID controller that use the modified current shapes.

The simulation with MatLab ${ }^{\circledR}$ Simulink used 12,000 input data values (speed error, derivative of speed error, integral of speed error and angular rotor position) distributed as 6000 for training, 3000 for test and 3000 for validation. On the other hand, 12,000 output data values (currents in three phases) were used, obtained with the simulation of the PID conventional controller.

For neural network training the MatLab ${ }^{\circledR}$ software was used ("nntool”). The neural network properties were: feed-forward back propagation network type, network training function that updates weight and bias values according to Levenberg-Marquardt optimization (TRAINLM), gradient descent with momentum weight and bias adaption learning function (LEARNGDM), mean squared error performance function (MSE), two layers: layer 1 using 36 neurons with hyperbolic tangent sigmoid transfer function (TANSIG) and layer 2 using 3 neurons with linear transfer function (PURELIN). Figure 9 shows the neural architecture and Figure 10 shows the performance of the neural network training used in the simulation.

The training generated weight and bias values of the two layers that were used in the neural PID controller to calculate the references currents of the simulation. In the actual implementation, a correspondent table was prepared.

\section{Controllers Implementation}

The hardware to control the AFSRM consists of a controller circuit, three power converter circuits, one for each phase, a position sensor circuit, three Hall Effect current measurement circuits, also one for each phase, a torque meter connected between the AFSRM shaft and the mechanical load shaft. The shaft of a DC machine was used as an inertial load. These components are arranged as shown in the block diagram of Figure 11.

The experimental hardware is shown in Figure 12, including the AFSRM. In this photo the parts of the hardware used in the experiments can be identified: the controller circuit (1), the power converter circuits (2), the position sensor circuit (3), Hall Effect current measurement circuits (4), torque sensor and display (5), the AFSRM (6) and the DC machine (7).

The position sensor consists of an infrared optical circuit and an aluminum dish with 180 holes, fixed to the rotor structure. The signal from the sensor is transformed into a rectangular pulse stream with amplitude of $5 \mathrm{~V}$, 


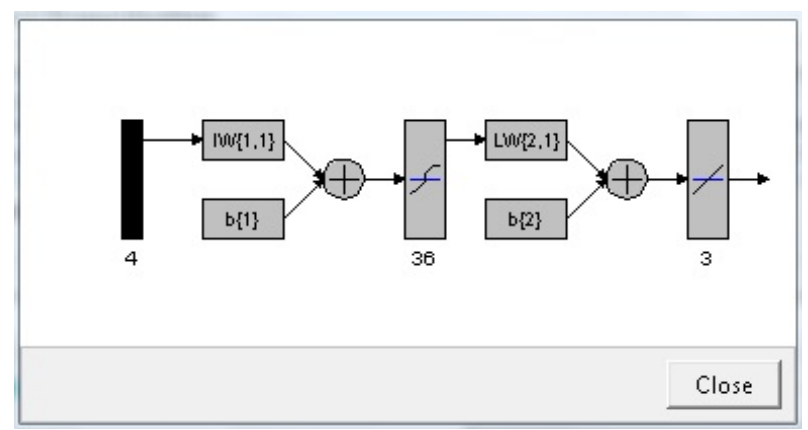

Figure 9. Neural architecture generated by "nntool" of the MatLab $^{\circledR}$ software.

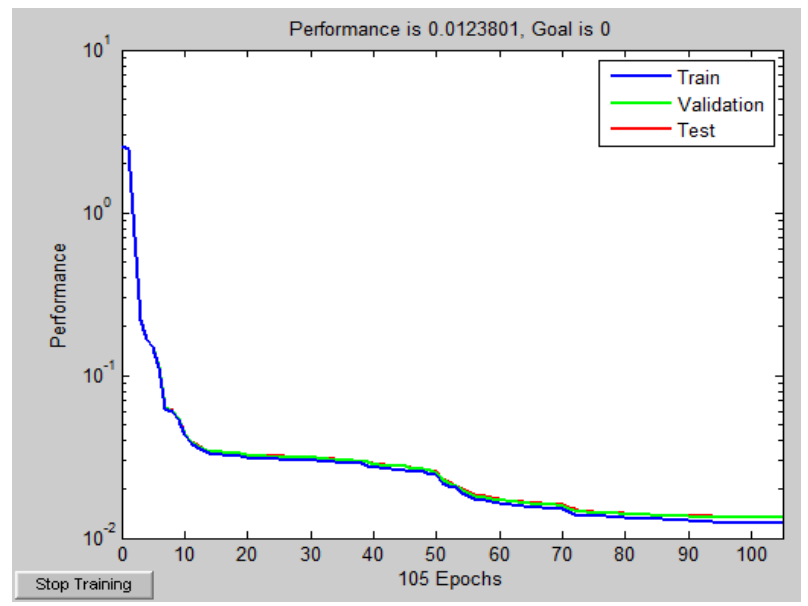

Figure 10. Neural network training of the MatLab ${ }^{\circledR}$ software.

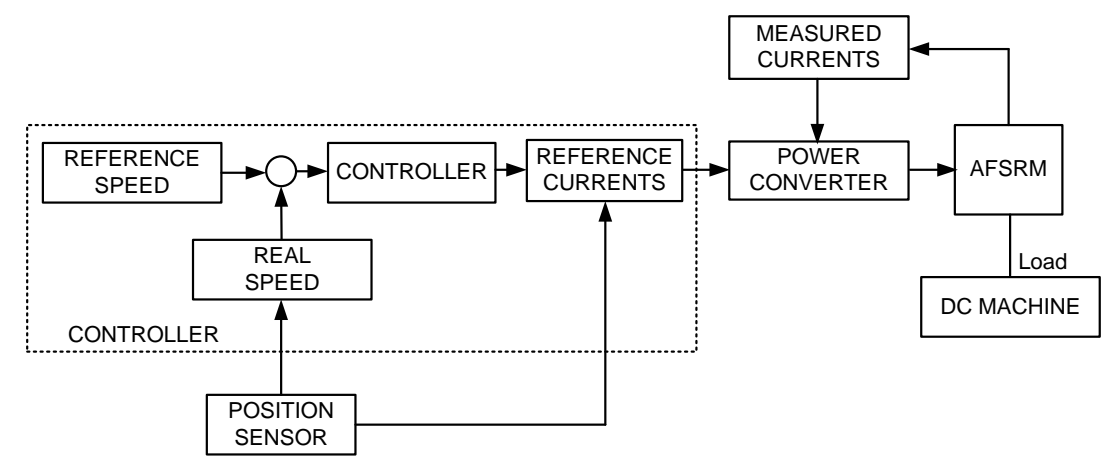

\section{Figure 11. AFSRM drive block diagram.}

which is sent to the controller circuit.

The actual phase currents are measured using commercial Hall Effect circuits. Their gain and zero adjustments were done in order to obtain $1 \mathrm{~V}$ for $1 \mathrm{~A}$ of phase current.

The power circuits consist of three asymmetric bridge converters and auxiliary circuits. In Figure 13, one of the power circuits is depicted.

As illustrated, the actual measured current is compared with the reference current coming from the controller circuit. If the real current is greater than the reference, the power circuit switches off the Mosfets of this phase in order to decrease the current in the coils.

The controller circuit consists of one microcontroller PIC 18F4680, programmed using the "C" language, that receives the rectangular pulses from the position sensor and calculates the reference currents of the three phases 


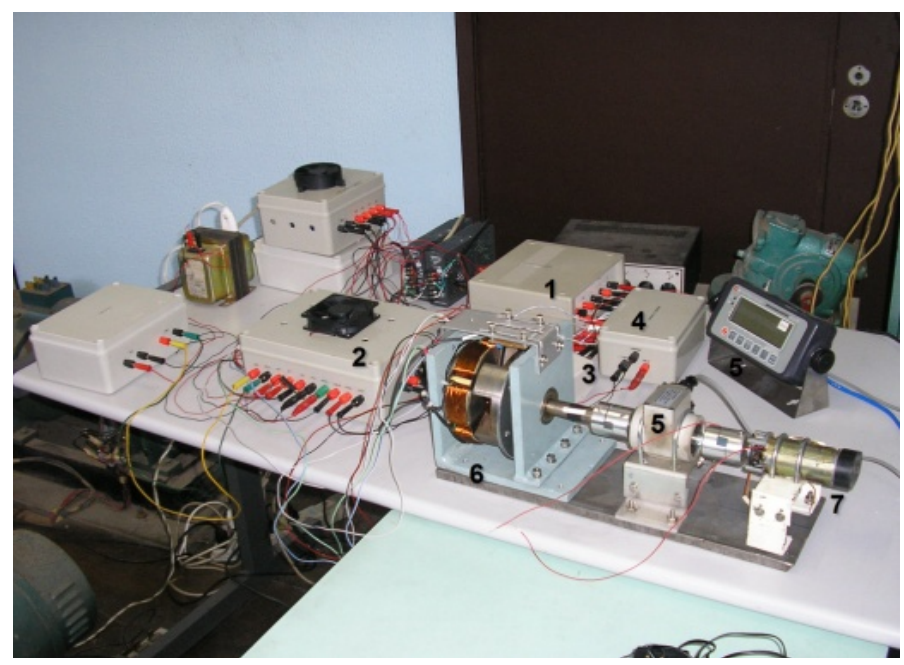

Figure 12. Experimental hardware and AFSRM prototype.

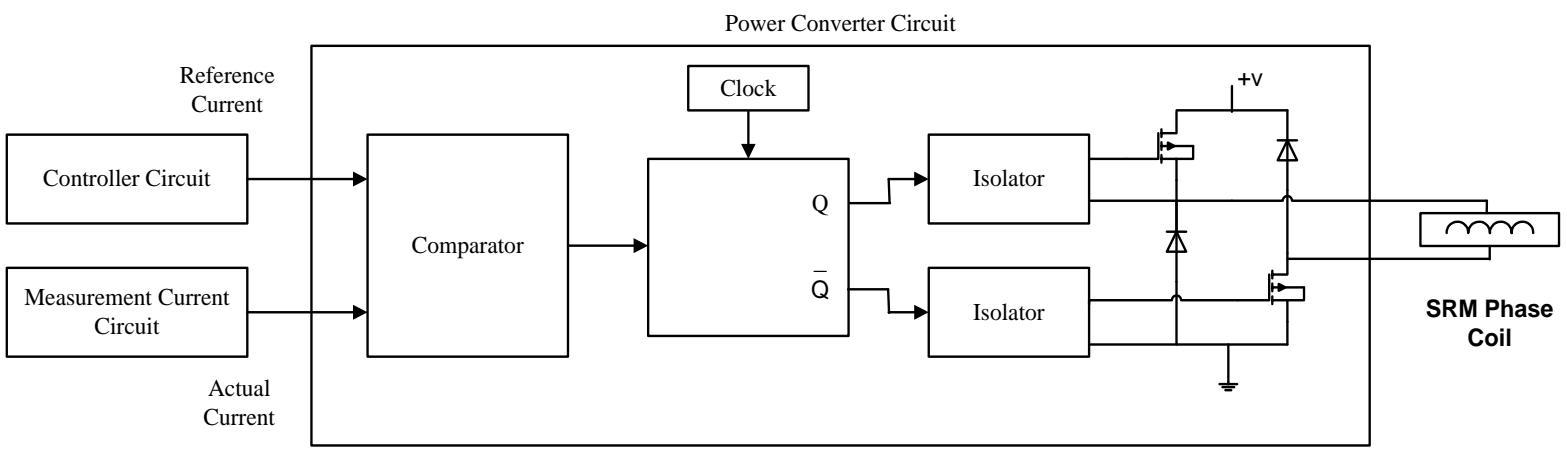

Figure 13. Power converter block diagram for one phase.

in accordance with the controller type used, sending them to the power converter. Due to the 180 holes in the aluminum dish, the controller imposed the reference currents every $2^{\circ}$.

\section{Experimental Results}

In order to evaluate the torque ripple minimization strategy, four experiments were performed:

- current pulses were imposed and a conventional PID speed controller was used;

- proposed current waveforms, shown in Figure 4, were imposed and a conventional PID speed controller was used;

- a fuzzy logic PID speed controller was used;

- a neural PID speed controller was used.

\subsection{Imposing Current Pulses}

In this case the current pulses were applied in the following sequence:

- phase " $a$ " from rotor position $0^{\circ}$ to $30^{\circ}$;

- phase " $c$ " from rotor position $30^{\circ}$ to $60^{\circ}$;

- phase " $b$ " from rotor position $60^{\circ}$ to $90^{\circ}$.

The Figure 14 shows the reference current imposed by the controller and the actual current in the coils of one phase.

The Figure 15 shows the speed response and the Figure 16 shows the torque response, when current pulses are imposed and a conventional PID speed controller is used. The reference speed is $350 \mathrm{rpm}$.

In this case, the torque ripple in steady state was around $17.1 \%$ of the average torque. 


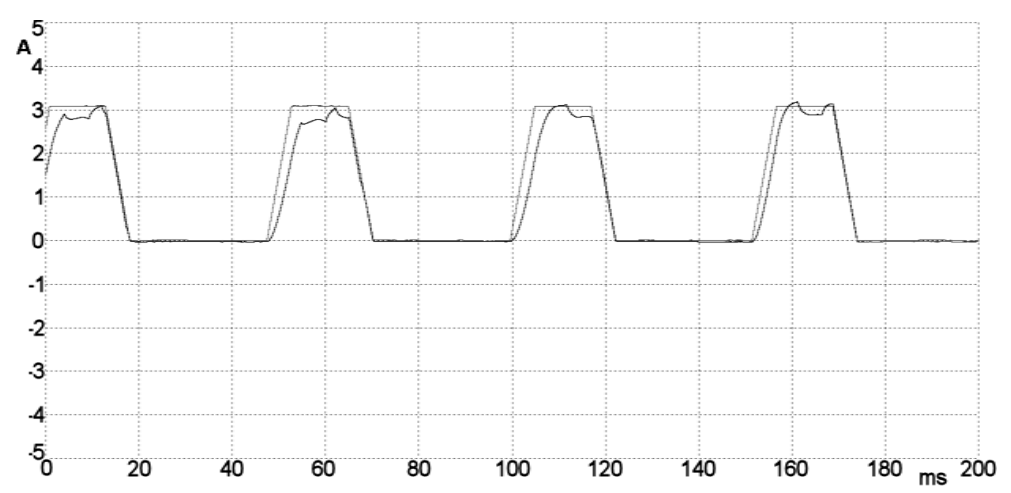

Figure 14. Reference pulsed current and real current.

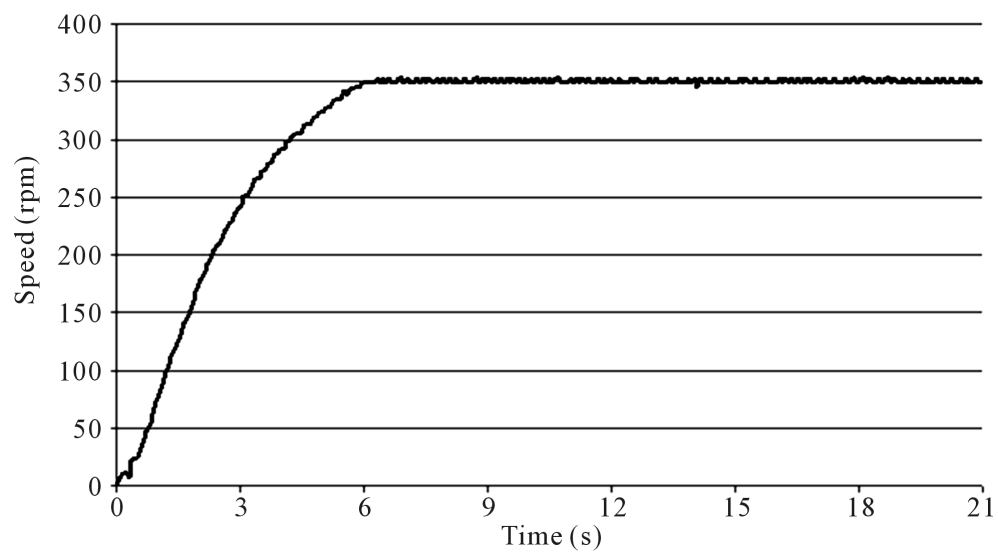

Figure 15. Speed response for current pulses and PID conventional speed controller.

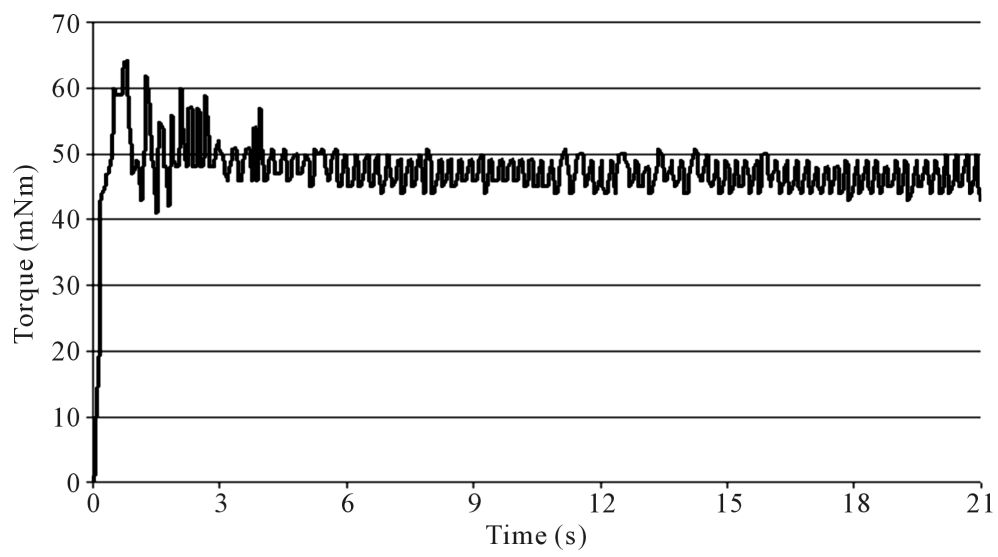

Figure 16. Torque response for current pulses and conventional PID speed controller.

\subsection{Imposing Proposed Current Waveforms}

The current waveform proposed as reference and the actual current in phase " $a$ " are shown in Figure 17.

Note that the actual and reference currents are practically overlapping.

The Figure 18 shows the speed response and Figure 19 shows the torque response for current waveforms proposed and conventional PID speed controller.

In this case, the torque ripple in steady state was around $2.1 \%$ of the average torque. 


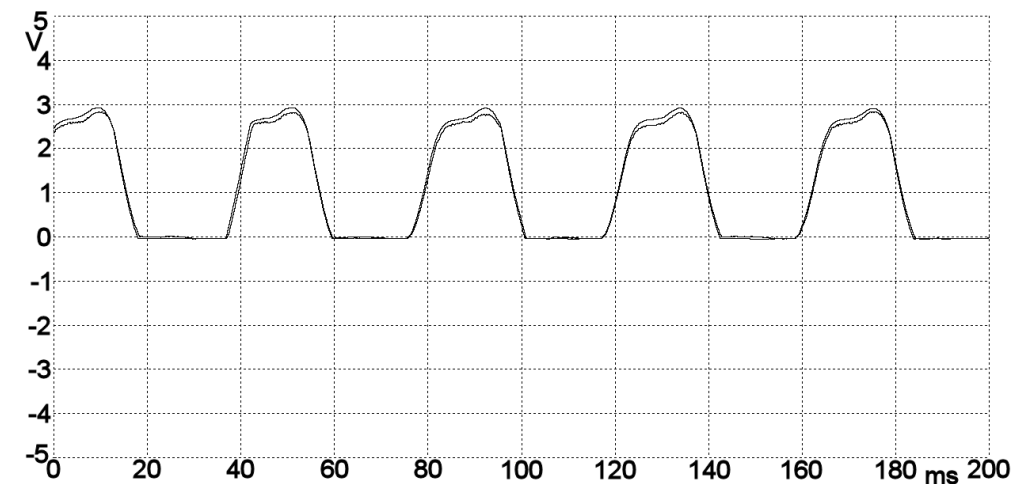

Figure 17. Proposed current reference and actual current.

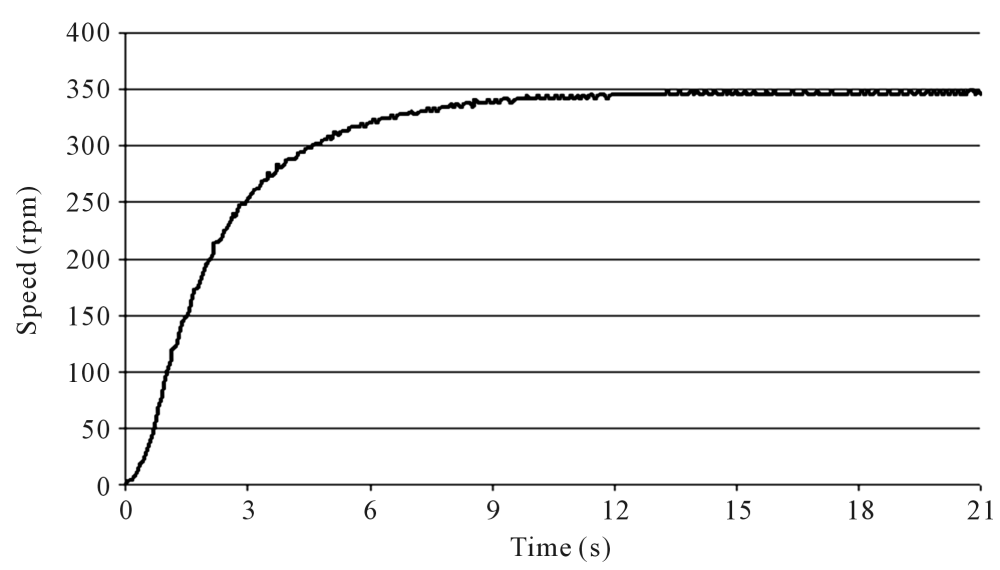

Figure 18. Speed response for current waveforms proposed and conventional PID speed controller.

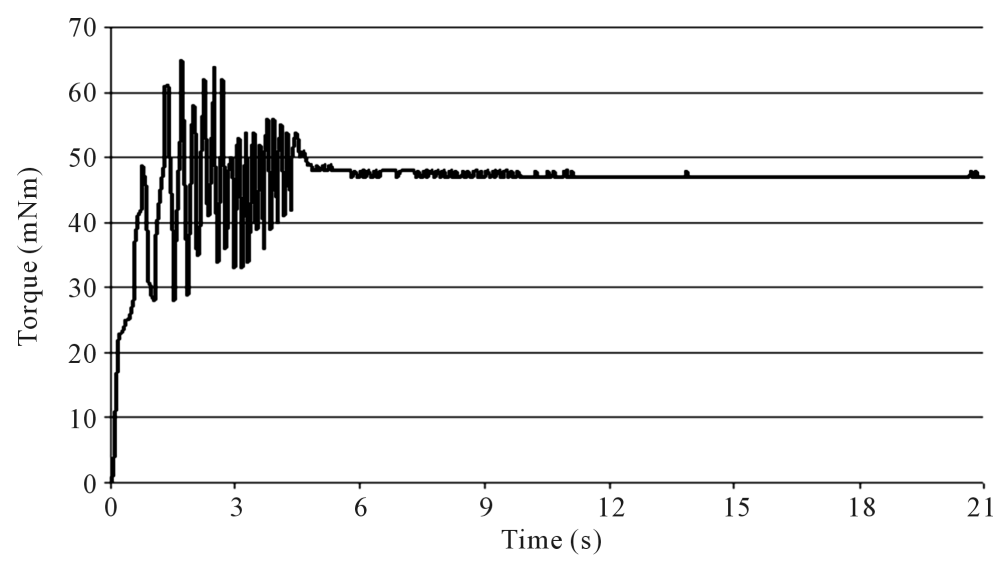

Figure 19. Torque response for current waveforms proposed and conventional PID speed controller.

\subsection{Using Fuzzy Logic PID Speed Controller}

The actual currents in two phases of the AFSRM are shown in Figure 20. These were very close to their references.

Figure 21 shows the speed response and Figure 22 shows the torque response for the fuzzy logic PID controller.

In this case, the torque ripple in steady state was around $6.5 \%$ of the average torque. 


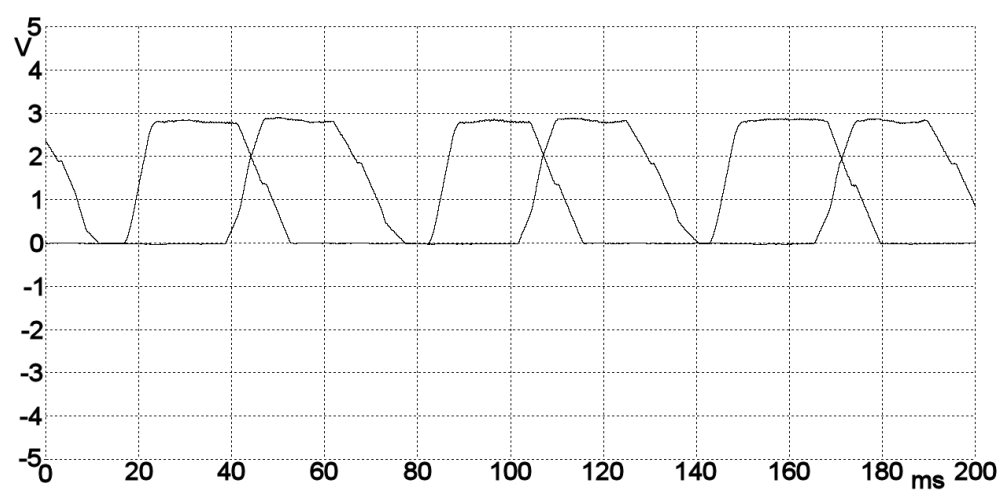

Figure 20. Actual currents of two phases using the fuzzy logic PID controller.

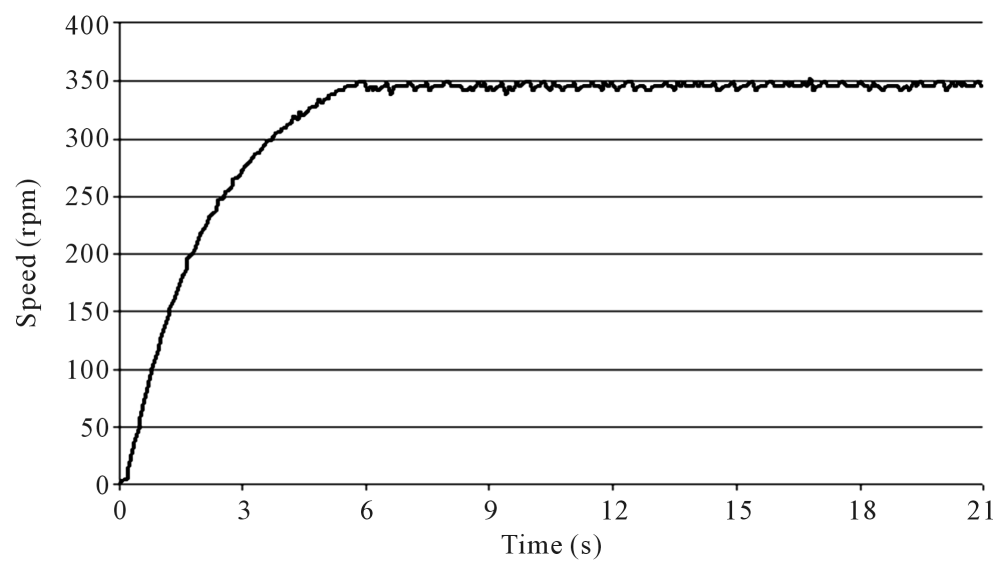

Figure 21. Speed response for the fuzzy logic PID controller.

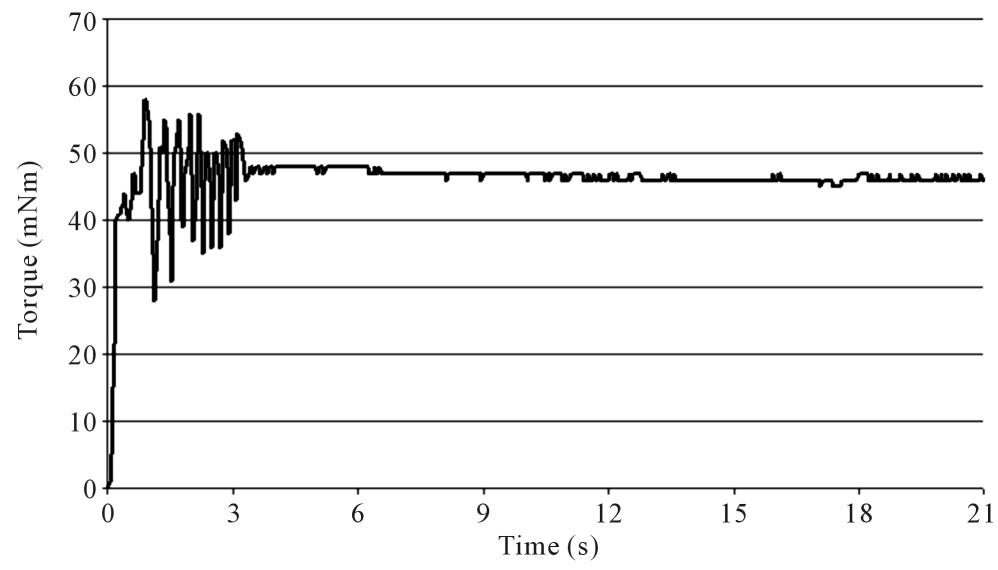

Figure 22. Torque response for the fuzzy logic PID controller.

\subsection{Using Neural PID Speed Controller}

The actual currents in two phases of the AFSRM are shown in Figure 23.

The Figure 24 shows the speed response and the Figure 25 shows the torque response for neural controller. In this case, the torque ripple in steady state was around $2.0 \%$ of the average torque.

\section{Conclusions}

In this work, particular reference waveforms for the currents of an ASFRM in a closed loop speed control 


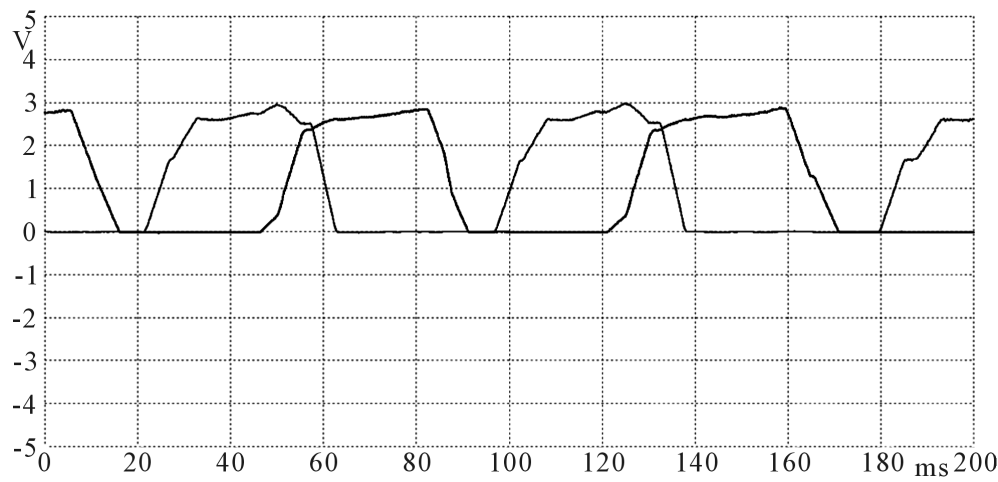

Figure 23. Actual currents of two phases using the neural PID controller.

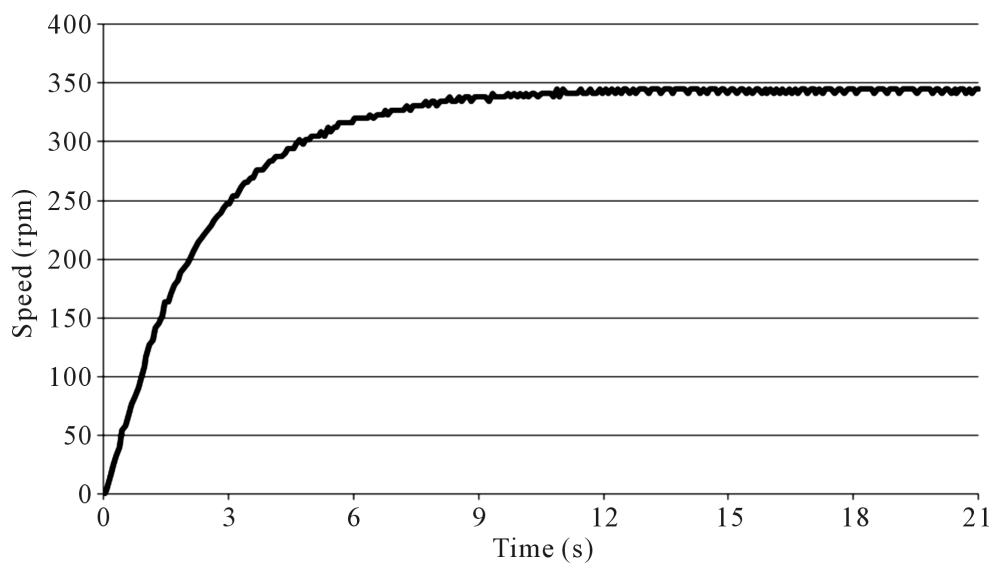

Figure 24. Speed response for neural PID controller.

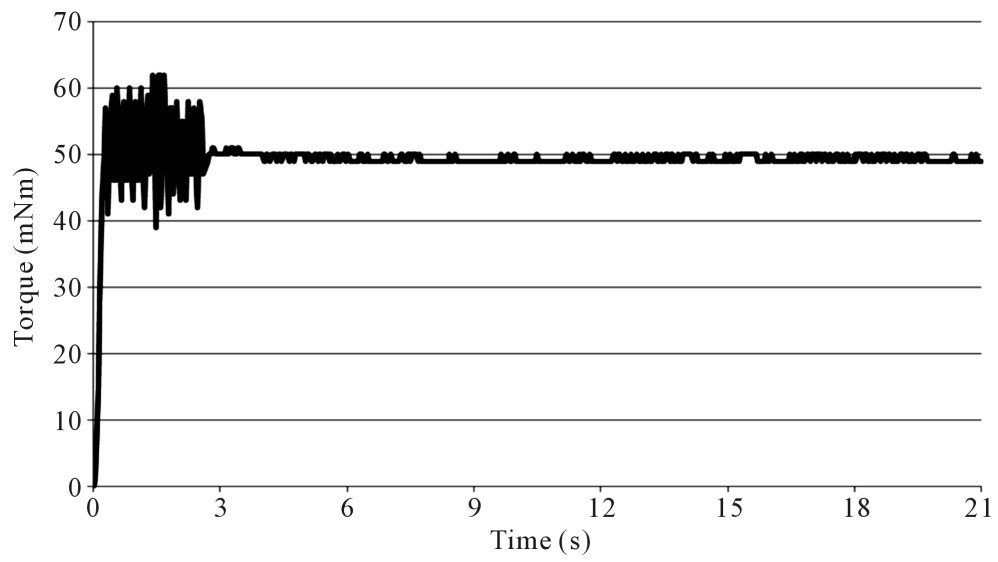

Figure 25. Torque response for neural PID controller.

system have been proposed and experimentally tested. Comparing the performance of a conventional PID speed controller using current pulses with a conventional PID speed controller, using the current waveforms proposed, it is confirmed that the level of torque ripple is reduced.

All the controllers were adjusted through simulations, using a motor model that is composed by self and mutual inductances obtained through 3D FEM simulations.

Comparing the performance of a conventional PID speed controller using the proposed current waveforms with a fuzzy logic PID speed controller, it was noted that the torque ripple for the first one is lower, which can be explained because the currents obtained with fuzzy logic controller are not exactly similar to those that would 
produce constant torque.

Nevertheless, in respect of the speed response, the fuzzy logic PID controller reaches the steady state in less time than the conventional PID controller. Even more, with respect to the implementation, the execution time of the fuzzy logic PID is lower than that used with the conventional PID controller but similar to that spent by the neural PID controller.

Finally, with respect to the neural PID controller, it notes similar torque ripple to the conventional PID controller but lower than that obtained using the fuzzy logic approach, which is expected as this was obtained from training based on the conventional PID controller results. However, this has a cost, which is the time spent in off-line training.

\section{References}

[1] Krishnan, R. (2001) Switched Reluctance Motor Drives: Modeling, Simulation, Analysis, Design and Applications. CRC Press, Boca Raton. http://dx.doi.org/10.1201/9781420041644

[2] Miller, T.J.E. (1993) Switched Reluctance Motors and Their Control. Oxford Science, Oxford.

[3] Vijayakumar, K., Karthikeyan, R., Paramasivam, S., Arumugam, R. and Srinivas, K.N. (2008) Switched Reluctance Motor Modeling, Design, Simulation, and Analysis: A Comprehensive Review. IEEE Transactions on Magnetics, 44, 4605-4617. http://dx.doi.org/10.1109/TMAG.2008.2003334

[4] Huang, S., Luo, J., Leonardi, F. and Lipo, T.A. (2000) A Comparison of Power Density for Axial Flux Machines Based on General Purpose Sizing Equations. IEEE Transactions on Energy Conversion, 14, 185-192. http://dx.doi.org/10.1109/60.766982

[5] Madhavan, R. and Fernandes, B.G. (2013) Axial Flux Segmented SRM with a Higher Number of Rotor Segments for Electric Vehicles. IEEE Transactions on Energy Conversion, 28, 203-213. http://dx.doi.org/10.1109/TEC.2012.2235068

[6] Madhavan, R. and Fernandes, B.G. (2012) Comparative Analysis of Axial Flux SRM Topologies for Electric Vehicle Application. IEEE International Conference on Power Electronics, Drives and Energy Systems, Bengaluru, 16-19 December 2012, 1-6.

[7] Asghar, K. (2013) Analysis of Switched Reluctance Motor Drives for Reduced Torque Ripple Using FPGA Based Simulation Technique. American Journal of Information Sciences, 6, 1-11.

[8] Wadnerkar, V.S., Bhaskar, M.M., Das, T.R. and RajKumar, A.D. (2010) A New Fuzzy Logic Based Modeling and Simulation of a Switched Reluctance Motor. Journal of Electrical Engineering \& Technology, 5, 276-281. http://dx.doi.org/10.5370/JEET.2010.5.2.276

[9] Raj, E.F.I. and Kamaraj, V. (2013) Neural Network Based Control for Switched Reluctance Motor Drive. IEEE International Conference on Emerging Trends in Computing, Communication and Nanotechnology, 678-682.

[10] Paula, P.P., Silva, W.M., Cardoso, J.R. and Nabeta, S.I. (2003) Assessment of the Influences of the Mutual Inductances on Switched Reluctance Machines Performance. International Electric Machine and Drives Conference, 3, 1697-1701.

[11] ANSYS Inc. (2005) Low-Frequency Electromagnetics Analysis Guide: Release 10.0. ANSYS Inc., Canonsburg.

[12] Sass, F., Santisteban, J.A. and Sanches, E. (2009) Design and Implementation of a Digital Control System for an Axial Flux Switched Reluctance Motor. Brazilian Power Electronics Conference, Bonito, 27 September-1 October 2009, $138-144$. 
Scientific Research Publishing (SCIRP) is one of the largest Open Access journal publishers. It is currently publishing more than 200 open access, online, peer-reviewed journals covering a wide range of academic disciplines. SCIRP serves the worldwide academic communities and contributes to the progress and application of science with its publication.

Other selected journals from SCIRP are listed as below. Submit your manuscript to us via either submit@scirp.org or Online Submission Portal.
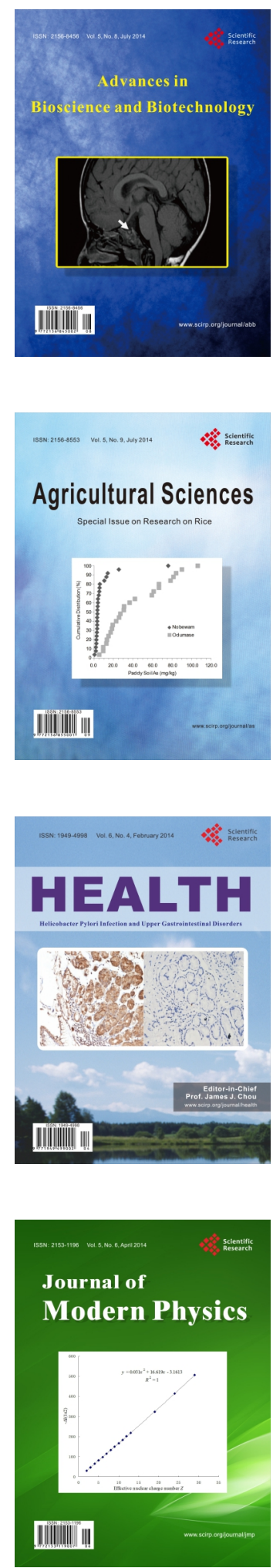
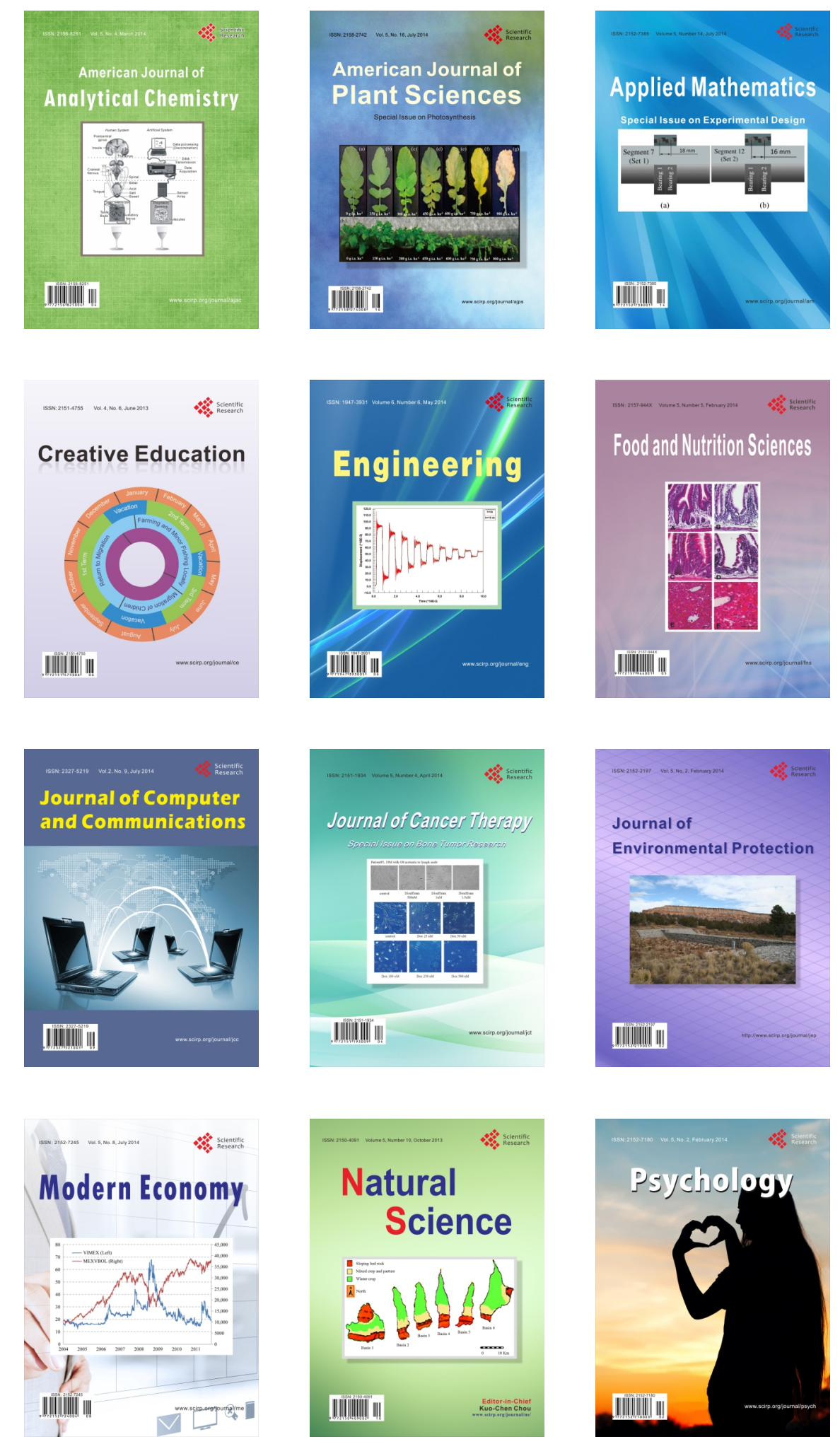